\title{
The Probe on the Children's English Acquisition
}

\author{
Changfu Sui \\ Daqing Petroleum Institute at Qinhuangdao, Qinhuangdao 066004, China \\ Tel: 86-335-887-4829 E-mail: scfzyq@yahoo.com.cn
}

\begin{abstract}
English has become the medium for communication in so many areas, and children are the hope of the future and shoulder the duties to structure the future. Children's English becomes more important and spreads all over the world, especially in recent years.

The children's English is not perfect and it exists its own disadvantages, so this paper gives four Optimizations and suggestions in teaching children's English in order to solve the problem. Then it lists several relations to the children's English study, and these four relations are very important because they are the keys to lead the children's English to a healthy and developing road. And in the next chapter, it talks about the trends of the children's English in the future and lists the reasons why these kinds of trends appear.
\end{abstract}

At last, overlook the whole paper and give a conclusion, which show that the children's English has a great potentiality in the future in China.

Keywords: Children's English, Language acquisition, Advantages and disadvantages, Relations, Trends

\section{Introduction}

As is known, the English language has become the dominant medium for communication worldwide in books, newspapers, magazines, international business, pop music, advertising, travel, and thanks to the Internet, English language proficiency has become a major requirement for attaining the highest level of professional and economic success around the world. And the children coming from all over the world are the main part of the studying English. Because they are the hope of the future and they shoulder the duties to structure their own societies. So children learning English is becoming a more important project in recent years. More and more parents pay increasing attention to children's English and more and more children join the study of children English. So the children's English training has already occupied a very important position in English training field. As the development of the children's English, a lot of gratifying achievements achieved. Li Zhejiang, a seven year old child, who conquers the judging panel and honorable foreign guests so as to the absolute advantage, obtains the champion of the preschool group of " national children's English elegance match"; In announcement in the CET -4 examination of score, an eleven years old boy passes the CET-4 examination a little just in Nanjing.

From these facts it is possible for children to learn English and do it well at a low age, even one month old, because children have the gifts to learn language.

\section{Language Acquisition}

\subsection{First language acquisition}

Babies are born with the ability to distinguish speech from other sounds they hear, even though they do not understand what they mean. By the time children reach school age, they are speaking in complex sentences, having conversations, and can understand most of what they hear. How does the development of language occur?

Children's brains are designed to help them learn language. From the time they are born, their brains register and process the sounds they hear. As a child's brain, thinking skills, and motor systems develop, so do his/her understanding and the use of language to communicate. Underlying language development is the ability to think about the world, and to explore it with vision, hearing, smell, touch, etc. As a child begins to make sense of the world through exploration, language is attached to those experiences. Language develops gradually, from single words at about twelve months to complex sentences at five years, and from simple concepts (juice, shoes) to those that are more abstract (frustrated, addition). School-age children continue to learn and use increasingly complex and abstract language.

Because early language develops through sensory exploration and understanding of the world, language development for a child with a visual impairment or deaf blindness will be effected by the nature and severity of the sensory impairments, and by other factors such as motor and cognitive skills. Some children with mind to moderate vision and hearing losses can be taught to compensate for limited visual and auditory information. They do this by using their other 
senses, thinking skills, and hands-on experiences to learn the meanings associated with words and sentences.

\subsection{Second language acquisition}

The development of a second language can occur in different ways. For example, a child may be exposed, from birth, to two languages at the same time; or a high school student might take a foreign language elective. I want to talk specifically about the children who learn a language other than English at home, then begin to learn English when they enter school. Depending on the parents' requests and services offered by the local district, these children may be placed in an English speaking classroom, an English as a Second Language (ESL) classroom, or a Bilingual Education classroom. It is important to note that a child's classroom placement will have an impact on the development of both first and second languages. Bilingual education classes foster development of skills in English and the child's first language. ESL classes only support skill development in English, a strategy that may be associated with slower acquisition of abstract language.

In general, these children enter school with proficiency in their native languages, which they then use as natural foundations for learning English. The process of acquiring English is gradual and follows a pattern of development similar to first language acquisition. For example, simple sentences are produced before complex ones. Children make errors in English that reflect the linguistic rules of their first language. For example, a Spanish speaking child may say, "I want the ball green," because in Spanish speech, adjectives are spoken after nouns. Conversational skills are acquired (in about 2 years) before the abstract language required in a classroom is fully developed (in 5 to 7 years). These children still learn language best through exposure and experiences.

Second language acquisition, however, often occurs during classroom activities where specific, targeted English skills are being taught, rather than through the hands-on experiences typical of first language acquisition. Children are challenged to learn English quickly, while keeping up with the new concepts introduced in their classes every day. They have little time to learn basic English before it must be understood and used in highly abstract and decontextualized academic activities.

\section{3 visual and auditory impairment and second language acquisition}

Generally, it has been assumed that if a child's first language develops normally, the second language will also develop normally. Why might this assumption NOT be true for children with visual impairments or deaf blindness?

Many professionals have observed that verbal children with visual impairments or deaf blindness sometimes have great difficulty acquiring a second language. They also may have difficulty transitioning from bilingual education to English-only instruction. I think the differences between learning a first and second language come from the ways those two languages are acquired. As with all children, verbal children with visual impairments or deaf blindness also learn their first language gradually, over many years. While the information they are getting from the environment is reduced, within the context of multiple, highly meaningful, multisensory experiences, other senses are used to support and compensate for limited visual and auditory information. A foundation of relatively normal language is built, upon which is added the complex language required in school.

Second language instruction in a classroom is by nature primarily visual and auditory. One language is used to teach another language, either through use of the first language or by simplified explanations of concepts in the second language. Because children are expected to use and understand abstract academic concepts in English almost immediately, they often don't have time to develop complex language gradually. Children with visual impairments or deaf blindness have difficulty compensating for the limited or distorted information received through their visual and auditory systems. They often cannot use touch, smell, taste, or movement to learn abstract concepts that are taught visually and auditorially. Therefore they must rely upon prior knowledge to understand what they are hearing and seeing. They can quickly and easily miss or misunderstand the concepts being taught.

\section{The analysis from two different points}

\subsection{The objective Analysis according to children's psychological characteristic}

Researcher analysis the activities of the brain to children and adult foreign language learners respectively and found finally, the children, while studying a foreign language, the brain stored it in "Brocas district", namely the same position as mother tongue, but adults are unable to store the foreign language in this district while studying the foreign language can only set up a memory structure in another position in brain again, and the new memory structure is not sensitive to the "Brocas district", and need to establish the connection with "Brocas district" while using. The position "Brocas district" that is responsible for studying the language in the brain is very developed and sensitive in people's childhood, and people's mother tongue is stored in this area promptly. But with the growth of age, the sensitivity of this area presents the downward trend.

The foreign scholar once studied to the victory mechanism that children studied mother tongue and the second language. For example Kim 1997 experiment research indicate, the children learn the second language very early, the study 
centers of its mother tongue and the second language are nearly on the same position of the brain; if children can study the foreign language with mechanism of mother tongue, it can have made the studies of second language very easily. There is scholar's research of doing brain radiography of functional nuclear magnetic resonance, find that studies the first language and the second language at the nearly same time, area deals with this bilingual to near, even overlap partly. Let children keep in touch with bilingual early, children inherent language learning mechanism can early accept two kinds of different languages amazingly, and the independence is developed. It is obvious, that the study of the mother tongue and study of the second language complement each other, and do not set against.

\subsection{The objective analysis to foreign language study}

There are various kinds of ability possessed often ignored or underestimated before children begin to study English. In fact, they have certain experience of life and have their own world, and are good at understanding the things around according to one's own way, and have already learnt a language at least. Study is an interdynamic course.

The theory of Vygotsky ZPD (Zone of proximal development) has emphasized the high-quality interdynamic contacts, for example, the interdynatic lead by adult or lead by someone who superior to one's own is very essential.

Holliday supports the interdynamic view too. He thinks "The study of mother tongue and the second, the third language is a cognitive course, it is an interdynamic course at the same time, its form of expression is oneself and others' successive exchange" (1975:139)

Communication language teaching rule regards it as its key thought to understand and transmit information; its importance has even exceeded the accuracy of the language. Fisher has emphasized the importance of talking in developing people's thought too. This is being echoed with another view of linking the Vygotsky: It is very important in development in an all-round way to stimulate and transform the thought into the course of the language.

The important principle of cooperating talk in meaning in the language has sufficient embodiment in teaching method communication language. In such true activity, the students exchange the views each other, and solve the true problem and reach the unanimous understanding. Obviously, all students need to think, it is not merely to state the objective fact to exchange the views; Cooperating talk has true meanings, which can just excite the talk interest of participants.

The child's task is to form the language system that can represent one's own social realistic mode meaning. This course will be produced in his head, and is a cognitive course. But its production needs an interdynamic environment in communication. Never have other methods that it emerges except this kind of environment. (Halliday 1975: 139)

Study is a positive and cognitive course. Child should not be filled with as a waiting empty pot, but should be a positive seeker of thought and language. Just as preceding paragraphs talked about, the child has already had many kinds of ability; all these are foundation stones of structuring the new abilities. Barnes describes like "we everyone can get the goal of learning through understanding the things around constantly and structure one's own world actively."

To the child who participants in the learning process actively in terms of cognition, what they need is the challenge and taking risks. Tasks or activities that offered have not certain challenges and child who takes the risk of, and the child's unable independence forever. Even stagnate at some time, lose the motive force of studying. But these challenges must have proper supports of teachers, classmates too, and accord with the theory of ZPD that put forward "New knowledge must in close to in the area, child of development level at the same time, promptly 'Zone of proximal development' ".

The importance in the second language which is studied of positive participation in this kind of learning process is self-evident too.

There are a lot of discussions about foreign language studying. For many years, people have always cut the language apart into the independent unit- the structure unit or the grammar unit-which were taught by professor bit by bit; then student spell piece of these together as playing picture arrangement game, then go to understand this language.

However, it is not such a course while the children studying the mother tongue. They place themselves in the midst of the wide language environment, absorb and use the intact language, and get to understand its structure and grammar in deeper subconscious Lewis (1993) advocated the foreign language teaching should set out from " language section or the intact language that a lot of vocabularies form" to develop the abilities to use intact language. Tough (Brumfit1991) has discussed to the function of "systematized language" in the classroom instruction too. Teacher should replace some vocabularies of language when child is talking at any time as mother at home, to form the new intact language.

It is regrettable that most adults and children are exposed to language in exercise and confined to level of sentence that "digest already" in studying in classroom. But in fact, teacher should not simplify the course of study so, and should be through specifying the study way of structurization, thus making students exposed to more complicated language environment. No matter how students' study habit, taste, ability, comprehensive development level and language development level are, they can get caught up in this kind of learning method. In children's English teaching, the teacher can use more stories, songs and directory, etc., and make students exposed to and study the intact language among the intelligible environment of language with real significance. 
The child does not choose the environment of the language while studying the first language; it is only a part in his daily life to study languages. They use the already existing knowledge to understand the new language phenomenon, set up the unknown from already known, and are adjusting the mode of thinking constantly through "absorbing or assimilating new knowledge dynamic course. All these analysis and theories can prove that children can acquire a second language. But everything has two sides, including the children's English. Now, let's talk about the next chapter.

\section{The advantages and disadvantages of children's English}

\subsection{The advantages}

\subsubsection{The natural advantages to learn English}

The research institution of American Cornell University publishes the thesis to point out on 1996 first "Nature": the position of the brains between the children and the adults use while studying foreign language are obviously different, cause adult speed to grasp foreign language far children rapidly. Adults study foreign language slow, grasp far firm, either relatively difficult to form the feeling for the language based on "Brocas district" as child does ,so, there are have certain advantages to learn foreign languages in childhood.

Childhood is the initial stage of the people's world outlook and values; it is the important stage to develop thinking ability and to form the cognitive way too. Different education contents and the ways and different environments have great influence on the development and cultivation of the above factors, so the child's development has greater plasticity in this stage.

\subsubsection{It is apt to train the interest}

Under the guide or influence of parents, teachers, classmates, children are very apt to become interested in fresh things. To English too, the children are interested in this fresh language.

\subsubsection{Psychological burden is light}

Because of the difference between English and Chinese and the culture between east and west, to Chinese, English is a kind of brand-new language, and it is more different to study English than to study other knowledge (for example mathematics, history). Someone thinks study foreign language is to "risk" to a great extent, offends the wrong danger. The psychological burden such as being so shy, timid, anxious is studied about foreign language bigger negative effects of persons who acquire. Comparing with the adult, they dare to open one's mouth; can participate in various kinds of activities actively. This helps to create the relaxing and happy study environment.

\subsubsection{The emotional factor is simple}

More and more research indicates, that the emotional factor is an important factor causing foreign language study differently. The emotional factor points the attitude and motive mainly. The learner's attitude includes two respects mainly: the attitude to study the target language; General attitude to the language and language study. We think, besides the above-mentioned two heavy, the foreign language learner's attitude still includes the attitude toward school and teacher, the attitude to the studying environment, attitude toward other learners (classmates), the attitude to studying material, etc. And respect these attitudes concrete; press close to reality even more, to more direct influences that foreign language study. Generally, children have simple thought and the attitude is positive, the above-mentioned kinds of attitudes, which we spoke of, cannot be problematic for children. Children study lean intuition and experience, lively study way and study enthusiasm of study with very apt to arouse them content that closely related to their life against generally, and arouse their interest to study foreign language.

\subsection{The disadvantages}

4.2.1 Children's psychological plasticity is strong, but automatic control ability is weak.

They are apt to train the interest, and apt to lose the interest too. If meet the setback or fail, or meet dull content of courses or teaching form, it is very easy for them to learn to lose the interest to learn about foreign language.

Children can enjoy studying in foreign language positively, but their concentrating time is limited. They are very easily to be influenced by external factors and disperse the attention.

\subsubsection{Children are not as good as adults in thinking ability}

They are not good at holding the system and law of the language; lack the ability of independent study. Lack the plan, arrangement to one's own study. The dependence on teacher is relatively strong.

\section{Optimization scheme and suggestion in teaching children's English}

First, the language should be intact, meaningful; closely relate to the real intact language helps children's absorbed listening even more, real understanding and application. Secondly, make the children feel languages are meaningful, easy to understand, and should put attention in the meaning that the language transmits. Moreover, the language is a tool socialized. Communicating, the content exchanged should be with the children's experience of life, the heart demand 
maintained close ties; it is independent, joyful, and effectual.

Second, the children's language learning is of many channels, and diversified forms. The language permeates in all the children's social behaviors. So, the teacher should not merely want to design meticulously, and organize the collective educational activities, but should pay close attention to children's moves about each link and their total language study and highly develop in family life.

Third, the children's language should get the positive response to expression. Language ability is not born. The child is communicating with the external world, always trying to use languages. It is essential to encourage children to dare to speak actively. Should go back or appraise the bold try, which supports the child for this teacher, help children to find, revise and create. Child is it take risks to worry only, is it make mistakes to fear, is it give language use effective resource of to store constantly, could control languages finally. As we know, "The more mistakes you make, the better student you will be."

The response and appraises that children get should be whenever and wherever, only in this atmosphere, they will just use boldly, positive application, initiative application.

Fourth, the foreign language teacher's quality is a very important too. Teachers should be study through specialized foreign language, and there are preschool professional knowledge and experience. This has very great front to influence to study about child's foreign language in the future.

\section{Several great relations to the children's English study}

\subsection{The relation between study Chinese and foreign languages}

From the practice of children's English teaching, there are two kinds of completely different methods. First, rely on Chinese. Some teachers regard Chinese as the only classroom term; often adopt the method to translating. Second, repel Chinese. Some teachers do not use definitely in each link of the foreign language teaching. I think, these two kinds of methods are both lost biased.

The teacher can make children draw support from Chinese, and children can learn English fast. If the teacher use Chinese to be apt, and use improper, can make Chinese become stumbling block, children of study.

\subsection{Positive effects of Chinese to study about foreign language}

For the children learning English at the beginning or younger children, teacher can use Chinese very among, and make it become child's walking stick to study foreign language. The teacher uses Chinese to be proper in good time, follows the rules from many to few decreasing, so as to ensure children have enough time to study foreign language in the activity. The teacher wants to expand the range that children are exposed to foreign language, makes children's foreign language learn to move towards other subjects, take each link of life for less than one day, and it lays the foundation for children with habit, foreign language of thinking to form.

\subsection{The relation between inputting and acquiring}

From inputting to acquire course that get, it is extremely important screening function for emotion not to play in second language. The child of its relation acquires the quantity and quality of the second language. Mood relaxes and feels comfortable children are while studying the second language, will study a little better than the children laden with anxiety, with quite old pressure.

We will input languages to children in lively form. The game, song, dance, rhythm, painting, listening to the story; it is in limbs movement, etc. that children yearn for very much for activity, should application not extensive.

Children make such a mistake like this or that during the process of using the language unavoidably, so long as do not influence normal teaching activity and associating the activity, teachers should not correct immediately, and should accept, in order to lighten children's psychological pressure, strengthen children's study confidence.

\subsection{The relation between the form of languages and social culture}

The language is a carrier of the culture. If one does not understand the mode and criterion of culture, then he cannot really learn languages well. As carrying on to children foreign language education, teacher should let children study foreign language systematic itself, and let children understand foreign language cultural environment, social customs and ways of thinking that language depends on for existence. For this reason, the teacher needs to proceed with two following respects.

First, improve one's own artistic appreciation. The education of children's English, teachers are not only teaching a kind of language, but teach a kind of culture at the same time. The teacher should widen one's own range of knowledge, and understand different culture and main characteristic, and establish and respect the pluralistic model for children.

Second, train children's cultural consciousness. Children studying English is not only for grasping one communication tool, but also for finding out about certain culture. The teacher should transmit the cultural information related to 
language to children simply but profoundly in good time.

In a word, children's English education has all sorts of dispute, we should hold to foreign language education that carry on already rigorous, high-standard demand, make its harmonious, lasting steady development.

\section{The future of the children's English}

\subsection{Children's English trends to American English}

On the one hand, there are lots of countries spoken English. For example, Britain, Iceland, Australia, they all speak Britain English. But America and Canada, they speak American English. Britain English has heavy regional accent. And all the parents are willing their children to speak English fluently and exactly. And American English just has these characteristics.

On the other hand, English, as other language, is changing developing constantly. And America has more great effects on it than Britain does. For example, the Internet and system of Window all stem from America and the American do not admit the spelling of Britain. Obviously, America is a great country in the terms of technology and economy, and if you want to get the newest information directly, the America English just offer you a convenient way .So we can get the result that children's English trends to American English in the future.

\subsection{Children's English will enter into the Internet}

Peter Duckers says, "Online education is the future education". And of course, including the children's English, because it is a very important part of the education. And the reasons of children's English entering the Internet are that the Internet is informative as well as interesting .It takes a wide variety of learning styles: audio video, record-and-playback, chat, games, slang, dictionary and so on. The internet is colorful and useful for children.

Apart from this, the Internet can deliver content in smaller units than a classroom course, promoting greater understanding and better retention of the material.

The interactive features of online courses are designed to allow learners to interact or communicate with thousands of other language learners around the world directly from learner's site so that they can learn from each other and help each other, which is something almost impossible for a single classroom or English training school to do on its own. Learners will surely value this opportunity to practice their skills with others, and therefore their language standard will be enhanced.

\section{Conclusions}

The children's English is not perfect. It also has its own obvious disadvantages from recent research . So how to solve these problems and drive the children's English to a normal way are necessary. The optimizations and suggestions in teaching children's English should be followed and practice them step and step and perfect it constantly. But the course is very difficult and it will be a long way to go.

In a word, the children's English has a great potentiality. Children can learn English and get knowledge meanwhile the children's English training school can get many benefits from the process. Both of them are the winners of children's English. As more and more parents pay attentions to children's English, training schools take more cares to children's English and more children join into children's English, the children's English will meets its great development and more glorious future in China soon.

\section{References}

Munoz, Language Assessment and Intervention with Children who have Visual Impairments, 1998

Snyder, Teaching English as a second language to blind people, 1972

Yao, Li., Cao, Ying. and Wang, Shangiiang., E-English: The Future of English Language Learning, Chinese English Teaching ,2003, Volume 1, Foreign Language Teaching and Research Press. 